\title{
Correction to: An online calibration tool for soft sensors: development and experimental tests in a semi-industrial boiler plant
}

Andréa Pereira Parente ${ }^{1} \cdot$ Andrea Valdman $^{1} \cdot$ Rossana Odette M. Folly ${ }^{1}$ Maurício Bezerra de Souza Jr ${ }^{1}$. Ana Maria Frattini Fileti ${ }^{2}$

Published online: 6 February 2020

○) Associação Brasileira de Engenharia Química 2020

Correction to: Brazilian Journal of Chemical Engineering https://doi.org/10.1007/s43153-019-00005-w

Due to a typesetting error the second name of the fourth author was wrong. The original article has been corrected.

Publisher's Note Springer Nature remains neutral with regard to jurisdictional claims in published maps and institutional affiliations.

The original article can be found online at https://doi.org/10.1007/ s43153-019-00005-w.

Andréa Pereira Parente parente@eq.ufrj.br

1 Centro de Tecnologia/Escola de Química, Universidade Federal do Rio de Janeiro, Av. Athos da Silveira Ramos, 149, Bloco E, Sala E-201, Ilha do Fundão, Caixa Postal 68542, Rio de Janeiro, RJ CEP 21941-909, Brazil

2 UNICAMP-FEQ-DESQ, Av. Albert Einstein, 500, Campinas, São Paulo 13083-852, Brazil 